\title{
Fungus-Growing Ants: Models for the Integrative Analysis of Cognition and Brain Evolution
}

\author{
Isabella B. Muratore ${ }^{1 *}$ and James F. A. Traniello ${ }^{1,2}$ \\ ${ }^{1}$ Department of Biology, Boston University, Boston, MA, United States, ${ }^{2}$ Graduate Program in Neuroscience, Boston \\ University, Boston, MA, United States
}

Keywords: cognitive ecology, behavior, social brain, ant, division of labor

Agents of selection for behavioral responses to abiotic, biotic, and social environments are described as cognitive challenges. Research integrating behavior, ecology, and brain evolution has generated a growing literature-and sometimes controversy-over inferences made from correlating cognitive traits with neural metrics. We propose that our understanding of the role of cognition in brain evolution can be advanced through studies of eusocial insect species differing in agricultural practices and degree of division of labor, and thus social complexity. Fungus-growing ants offer diverse systems to assess the impacts of cognitive challenges on behavioral evolution and its neural and genomic architectures. Workers exhibit variability in social role differentiation in association with diet, morphology, group size, and task efficiency. This suite of covarying traits enables the accurate mapping of cognition, worker repertoire breadth, neuroanatomy, and genomic change in

OPEN ACCESS

Edited by:

Clare C. Rittschof

University of Kentucky, United States

Reviewed by:

Christian Rabeling,

Arizona State University, United States

David Baracchi,

University of Florence, Italy

*Correspondence:

Isabella B. Muratore

imurator@bu.edu

Specialty section:

This article was submitted to

Learning and Memory,

a section of the journal

Frontiers in Behavioral Neuroscience

Received: 26 August 2020

Accepted: 23 November 2020

Published: 11 December 2020

Citation:

Muratore IB and Traniello JFA (2020)

Fungus-Growing Ants: Models for the

Integrative Analysis of Cognition and

Brain Evolution.

Front. Behav. Neurosci. 14:599234.

doi: 10.3389/fnbeh.2020.599234

\section{HOW DO BRAINS RESPOND TO COGNITIVE CHALLENGES?}

Cognition is difficult to universally define (Logan et al., 2018; Bayne et al., 2019) and measure (Rowe and Healy, 2014; Simons and Tibbetts, 2019). However, cognitive ecologists have developed definitions emphasizing divergent demands from behavioral niches and neurobiological capabilities (Balda and Kamil, 1989; Real, 1993; Shettleworth, 2000, 2010; Dukas and Ratcliffe, 2009; Lihoreau et al., 2019). Cognition should be linked to ecological adaptation to understand developmental and evolutionary brain plasticity. Cognitive capability is thus the product of selection for brain organization to adaptively increase computational power and reduce energetic costs. Metrics applied in the study of brain evolution range from genes and cells to nervous system topologies. Correlations between behavioral capabilities and tissue volume have been viewed critically (Herculano-Houzel et al., 2006, 2007; Healy and Rowe, 2007, 2013; Chittka and Niven, 2009; Godfrey and Gronenberg, 2019; Wartel et al., 2019), although in principle quantify brain investment. Functionally specialized brain compartments may develop allometrically (disproportionate scaling) through differential cell and tissue-type trajectories (Barton and Harvey, 2000; Hager et al., 2012), circuitry (Guzowski et al., 2005), neuron structure and function (Quiroga et al., 2005), and genetics (Hibar et al., 2015; Kohno and Kubo, 2019). These patterns provide fine-grain traits for evolutionary analyses.

Social environments can influence brain evolution. Primates distinguish rivals from allies and recall interaction histories. Social brain theory, which posits a positive correlation between brain volume and group size to track social relationships (Dunbar and Shultz, 2017), has been applied to eusocial insects (Lihoreau et al., 2012; Godfrey and Gronenberg, 2019). However, eusocial insect workers typically lack the competing demands of direct reproduction; their brains are functionally dedicated to altruistic labor, and cognitive challenges from specialized behavior can thus be more clearly circumscribed. Diverse social systems enable the functional analysis of mosaic brains and 
responsiveness to divergent sensory demands underpinning task specialization (Muscedere and Traniello, 2012; Giraldo et al., 2013; Gordon et al., 2017). Two eusocial insect clades-a tribe of ants and a subfamily of termites-include ultrasocial species (Campbell, 1982) that are agriculturalists, producing their own crops of gongylidia-nutritional fungal swellings-and have evolved complex division of labor. These traits are shared with humans (Gowdy and Krall, 2016). Ant societies, as models, can be experimentally dissected (Kennedy et al., 2017), enabling studies of cognitive variation in association with the evolution of division of labor.

Assessing motivated behavior in natural contexts (Rowe and Healy, 2014) and selecting comparative frameworks illustrating divergence in cognitive challenges across related species (Simons and Tibbetts, 2019) are essential to link fitness to behavioral evolution. Therefore, to determine cognitive impacts on brain evolution, a model system should meet the following criteria: (1) the natural behavioral environment can be measured to assess sensory and processing requirements; (2) behavior can be quantified at multiple levels of intraspecies and interspecies biological organization; and (3) the metrics used to identify neural and genomic underpinnings are methodologically and statistically robust. With these points in mind, we identify fungus-growing ants as appropriate and insightful study models for cognitive evolution.

\section{DIVISION OF LABOR AND WORKER COGNITION}

The evolution of division of labor in support of agriculture in fungus-growing ants enables societal and individual cognition to be examined. Workers vary morphologically (monomorphism to exceptional polymorphism) and behaviorally (task pluripotency to specialization) across species and within colonies (Mehdiabadi and Schultz, 2010). In highly polymorphic leafcutting ants, colonies are large and may produce size-differentiated workersfor example, minims, medias, and majors in order of increasing size. This variation in body size, colony size, and diet can help disentangle confounding factors that may obscure the linkage of neuroanatomy to behavior. Fungus-growing ants select, harvest, and process plant tissue and other substrates to provide for fungal growth, cultivate fungus, manage waste and control infection, construct and maintain the nest and regulate microclimate, and provide defense. Workers with specialized repertoires are predicted to be more efficient than generalists (Wilson, 1980b). In theory, drivers of worker task performance may differ, but in polymorphic species body size and behavior are integrated and clearly correlate (Beshers and Fewell, 2001). Cognitive needs vary according to role and worksite: tasks performed within the nest by fungal-garden tenders require different stimulus-processing capabilities than foragers or defenders working outside the nest or at multiple worksites. Identifying, cutting, transporting, and mulching leaves forms an assembly line of exterior to interior work where leaf fragments are degraded as they are passed from larger to smaller workers and eventually deposited as fungal mulch. Worker size-related labor therefore requires specific motivation and cognitive abilities.

Minim workers primarily transplant and prune gongylidia. Working in dark underground fungal chambers, they likely rely on sensory inputs other than vision for navigation, which may involve the central complex (Plath and Barron, 2015; Honkanen et al., 2019). They also nurse, recognizing larval needs and discriminating brood stages, and assess humidity and temperature to maintain optimal growth conditions. These tasks involve chemical signals (Schultner and Pulliainen, 2020) processed by the antennal lobes and mushroom bodies, as well as fine motor coordination of the mouthparts, mediated by subesophageal zone circuitry (Paul and Gronenberg, 2002). Minims may deposit pheromones on foraging trails (Howard, 2001; Evison et al., 2008), clean contaminants from incoming leaves and otherwise protect the fungus from microbes (Goes et al., 2020), and defend against parasitic flies (Feener and Moss, 1990).

Media workers engage in diverse tasks. Large-scale agriculture requires evaluating diverse plant chemistries to assess leaf quality and maximize fungal growth (Hubbell et al., 1984; Howard et al., 1988; Saverschek et al., 2010). This discrimination may require learning. Also, the gustatory and olfactory processing abilities of medias should be well developed. Media worker skill in cutting leaves (Wilson, 1980b) requires compass-like coordination of legs and mandibles that determines leaf fragment size, facilitating size-assortative load-bearing for transport (Wilson, 1980a; Burd, 2000; Burd and Howard, 2008). Medias navigate trails between food sources and the nest. In many ants, this process involves recalling landmarks, using odometry and optic flow to measure speed and distance, learning canopy patterns and celestial cues, and decoding chemical recruitment information (Ronacher and Wehner, 1995; Wittlinger et al., 2006; Provecho and Josens, 2009; Basten and Mallot, 2010; Müller and Wehner, 2010; Steck, 2012; Heinze et al., 2018). Media worker foraging thus requires processing multimodal signals through interplay between the antennal and optic lobes, mushroom bodies, and central complex. Behavioral flexibility may be reflected in enlarged mushroom bodies (Farris, 2013), a pattern expected in media brains, but not minims or majors.

Majors defend against army ants and other enemies (Powell and Clark, 2004). Defensive may require close-range vision, mediated by the optic lobes (Via, 1977), and antennal lobe and mushroom body tuning to recruitment and alarm pheromones (López-Riquelme et al., 2006; Mizunami et al., 2010). Differences in task biomechanical demands are evident in subcaste myology (Gronenberg et al., 1997; Paul and Gronenberg, 1999, 2002): larger mandibular muscles provide majors with bite force, controlled in part by the subesophageal zone.

\section{SOCIAL AND PHYLOGENETIC PERSPECTIVES ON COGNITIVE EVOLUTION}

Fungus-growing ant species richness (>230 species; Schultz and Brady, 2008) encompasses exceptional heterogeneity 
in agricultural practice and social complexity. Behavioral phenotypes evolved greater specialization through developmental divergence in worker morphology (Mehdiabadi and Schultz, 2010; Sosa-Calvo et al., 2018; Solomon et al., 2019). The diversity of worker phenotypes in leafcutting genera such as Atta and Acromyrmex, which cultivate large quantities of fungus and form colonies of millions of polymorphic workers, is thought to have evolved from an ancestral monomorphic, generalist worker caste (Wilson, 1980a). The ancestral worker phenotype is evident in the paleoattini: these species form small colonies of monomorphic workers that engage in basic agriculture, scavenging insect frass and other materials for fungal substrate. Repertoire breadth is thought to influence brain size: performing more kinds of tasks requires greater processing power (Benson-Amram et al., 2016). A specialist worker of a polymorphic neoattine species would be relatively free of the constraints of maintaining a generalist repertoire and could evolve to prioritize neural capabilities specified by its task set. Size-differentiated workers display disproportionate scaling in morphology and physiology related to social roles that affect task efficiency (Wilson, 1980b). Selection should also be evident in brain structure in both attine clades. In sum, worker morphology, behavior, and brain size and structure are predicted to be integrated.

\section{SOCIETIES, BRAINS, AND GENOMES}

Ecological niche differentiation, and thus variability in cognitive needs across attine species and among neoattine worker subcastes, is remarkable. In some socially complex species, brain size (Seid et al., 2011), investment in vision-related compartments (Arganda et al., 2020), and microprocessing circuitry (Groh et al., 2014) vary with worker size. Brain volume decreases and antennal lobe volume increases with social group size in monomorphic species, suggesting decreased selective pressures on brain size coupled with a need for increased olfactory social discrimination (Riveros et al., 2012). Larger Atta workers have an antennal lobe macroglomerulus, absent in smaller workers, that likely functions in trail following (Kleineidam et al., 2005). Increased volume in visual processing regions in $A$. cephalotes majors allows greater visual acuity and processing in workers active in light and engaging in closerange defense (Arganda et al., 2020). Neuroanatomical and neurochemical variation (Smith et al., 2013) should integrate with brain gene expression to control behavior (Li et al., 2014; Qiu et al., 2018), enabling neural requirements of specific roles to be met.

Genetic analyses offer mechanistic and evolutionary insight into agriculturally adapted brains. Gene expression regulating attine ant neural phenotypes and behavior (Castillo and Pietrantonio, 2013; Koch et al., 2013) may be influenced by epigenetics, RNA editing, and copy number, as in related systems (Chittka et al., 2012; Scholes et al., 2013; Feldmeyer et al., 2014; Li et al., 2014). Developmental switches mediating size-related differentiation (Rajakumar et al., 2012, 2018) and differentially expressed brain gene modules related to caste determination (Qiu et al., 2018) appear conserved, although some worker-biased genes are more evolutionarily novel (Feldmeyer et al., 2014; Mikheyev and Linksvayer, 2015; Schrader et al., 2017). Deep brain homologies in eusocial insects (Tomer et al., 2010; Shpigler et al., 2017; Trible et al., 2017) provide broadly translatable insights into adaptive brain evolution and development, and their genomic basis.

\section{FUTURE RESEARCH}

The ability to identify mechanisms of response to cognitive challenges within phylogenetic context facilitates understanding brain evolution in light of socioecological selective forces. This allows the relative importance of task repertoire breadth and social structure to be examined. Studies that assess the same properties of learning (speed and memory, e.g.,) but consider species-specificity in behavior across size-variable workers in paleo-and neoattine ants can elucidate effects of social complexity on brain evolution. Comparative studies of neuroanatomical scaling and genomics enable variation in task diversity and sensory environments to be mapped onto fungus-growing ant phylogeny to reveal evolutionary patterns. Gene functions influencing neuroanatomy and behavior can reveal the relative importance of metabolism, neurotransmission, growth factors, and other pathways in the evolution of division of labor. The contrast between simple societies of monomorphic fungus-growing ants and complex colonies of leafcutting ants provides opportunities to examine genomic evolution in the brain. With increasingly precise genetic tools available for ant research, components of neural and anatomical phenotypes may be separated and linked to developmental origins. Ultimately, functional manipulations and genomic data will enable the identification of neurogenetic traits associated with cognitive evolution.

\section{AUTHOR CONTRIBUTIONS}

IM and JT drafted and edited the manuscript. JT secured funding. Both authors contributed to the article and approved the submitted version.

\section{FUNDING}

This work was supported by the Brenton R. Lutz award to IM and National Science Foundation grants IOS 1354291 and IOS 1953393 to JT.

\section{ACKNOWLEDGMENTS}

We gratefully acknowledge the insights of Sara Arganda, Sam Beshers, Zach Coto, and Frank Azorsa in developing the manuscript, and the comments of Clare Rittschof and two reviewers. 


\section{REFERENCES}

Arganda, S., Hoadley, A. P., Razdan, E. S., Muratore, I. M., and Traniello, J. F. A. (2020). The neuroplasticity of division of labor: worker polymorphism, compound eye structure and brain organization in the leafcutter ant Atta cephalotes. J. Comp. Physiol. A 206, 651-662. doi: 10.1007/s00359-020-01423-9

Balda, R. P., and Kamil, A. C. (1989). A comparative study of cache recovery by three corvid species. Anim. Behav. 38, 486-495. doi: 10.1016/S0003-3472(89)80041-7

Barton, R. A., and Harvey, P. H. (2000). Mosaic evolution of brain structure in mammals. Nature 405:1055. doi: 10.1038/35016580

Basten, K., and Mallot, H. A. (2010). Simulated visual homing in desert ant natural environments: efficiency of skyline cues. Biol. Cybern. 102, 413-425. doi: 10.1007/s00422-010-0375-9

Bayne, T., Brainard, D., Byrne, R. W., Chittka, L., Clayton, N., Heyes, C., et al. (2019). What is cognition? Curr. Biol. 29, R608-R615. doi: 10.1016/j.cub.2019.05.044

Benson-Amram, S., Dantzer, B., Stricker, G., Swanson, E. M., and Holekamp, K. E. (2016). Brain size predicts problem-solving ability in mammalian carnivores. Proc. Natl. Acad. Sci. U. S. A. 113, 2532-2537. doi: 10.1073/pnas.1505913113

Beshers, S. N., and Fewell, J. H. (2001). Models of division of labor in social insects. Annu. Rev. Entomol. 46, 413-440. doi: 10.1146/annurev.ento.46.1.413

Burd, M. (2000). Body size effects on locomotion and load carriage in the highly polymorphic leaf-cutting ants Atta colombica and Atta cephalotes. Behav. Ecol. 11, 125-131. doi: 10.1093/beheco/11.2.125

Burd, M., and Howard, J. J. (2008). Optimality in a partitioned task performed by social insects. Biol. Lett. 4, 627-629. doi: 10.1098/rsbl.2008.0398

Campbell, D. T. (1982). Legal and primary-group social controls. J. Soc. Biol. Struct. 5, 431-438. doi: 10.1016/S0140-1750(82)92071-1

Castillo, P., and Pietrantonio, P. V. (2013). Differences in sNPF receptorexpressing neurons in brains of fire ant (Solenopsis invicta Buren) worker subcastes: indicators for division of labor and nutritional status? PLOS ONE 8:e83966. doi: 10.1371/journal.pone.0083966

Chittka, A., Wurm, Y., and Chittka, L. (2012). Epigenetics: the making of ant castes. Curr. Biol. 22, R835-R838. doi: 10.1016/j.cub.2012.07.045

Chittka, L., and Niven, J. (2009). Are bigger brains better? Curr. Biol. 19, R995R1008. doi: 10.1016/j.cub.2009.08.023

Dukas, R., and Ratcliffe, J. M. (eds.). (2009). Cognitive Ecology II. Chicago, IL: University of Chicago Press.

Dunbar, R. I. M., and Shultz, S. (2017). Why are there so many explanations for primate brain evolution? Philos. Trans. R. Soc. B 372:20160244. doi: $10.1098 / \mathrm{rstb} .2016 .0244$

Evison, S. E., Hart, A. G., and Jackson, D. E. (2008). Minor workers have a major role in the maintenance of leafcutter ant pheromone trails. Anim. Behav. 75, 963-969. doi: 10.1016/j.anbehav.2007.07.013

Farris, S. M. (2013). Evolution of complex higher brain centers and behaviors: behavioral correlates of mushroom body elaboration in insects. Brain Behav. Evolut. 82, 9-18. doi: 10.1159/000352057

Feener, D. H., and Moss, K. A. (1990). Defense against parasites by hitchhikers in leaf-cutting ants: a quantitative assessment. Behav. Ecol. Sociobiol. 26, 17-29. doi: 10.1007/BF00174021

Feldmeyer, B., Elsner, D., and Foitzik, S. (2014). Gene expression patterns associated with caste and reproductive status in ants: worker-specific genes are more derived than queen-specific ones. Mol. Ecol. 23, 151-161. doi: $10.1111 / \mathrm{mec} .12490$

Giraldo, Y. M., Patel, E., Gronenberg, W., and Traniello, J. F. (2013). Division of labor and structural plasticity in an extrinsic serotonergic mushroom body neuron in the ant Pheidole dentata. Neurosci. Lett. 534, 107-111. doi: 10.1016/j.neulet.2012.11.057

Godfrey, R. K., and Gronenberg, W. (2019). Brain evolution in social insects: advocating for the comparative approach. J. Comp. Physiol. A 205, 13-32. doi: 10.1007/s00359-019-01315-7

Goes, A. C., Barcoto, M. O., Kooij, P. W., Bueno, O. C., and Rodrigues, A. (2020). How do leaf-cutting ants recognize antagonistic microbes in their fungal crops? Front. Ecol. Evol. 8:95. doi: 10.3389/fevo.2020.0 0095

Gordon, D. G., Ilieş, I., and Traniello, J. F. (2017). Behavior, brain, and morphology in a complex insect society: trait integration and social evolution in the exceptionally polymorphic ant Pheidole rhea. Behav. Ecol. Sociobiol. 71:166. doi: $10.1007 / \mathrm{s} 00265-017-2396-\mathrm{z}$

Gowdy, J., and Krall, L. (2016). The economic origins of ultrasociality. Behav. Brain Sci. 39:e92. doi: 10.1017/S0140525X1500059X

Groh, C., Kelber, C., Grübel, K., and Rössler, W. (2014). Density of mushroom body synaptic complexes limits intraspecies brain miniaturization in highly polymorphic leaf-cutting ant workers. Proc. R. Soc. B 281:20140432. doi: 10.1098/rspb.2014.0432

Gronenberg, W., Paul, J., Just, S., and Hölldobler, B. (1997). Mandible muscle fibers in ants: fast or powerful? Cell Tissue Res. 289, 347-361. doi: $10.1007 / \mathrm{s} 004410050882$

Guzowski, J. F., Timlin, J. A., Roysam, B., McNaughton, B. L., Worley, P. F., and Barnes, C. A. (2005). Mapping behaviorally relevant neural circuits with immediate-early gene expression. Curr. Opin. Neurobiol. 15, 599-606. doi: 10.1016/j.conb.2005.08.018

Hager, R., Lu, L., Rosen, G. D., and Williams, R. W. (2012). Genetic architecture supports mosaic brain evolution and independent brain-body size regulation. Nat. Commun. 3:1079. doi: $10.1038 /$ ncomms 2086

Healy, S. D., and Rowe, C. (2007). A critique of comparative studies of brain size. Proc. R. Soc. B 274, 453-464. doi: 10.1098/rspb.2006.3748

Healy, S. D., and Rowe, C. (2013). Costs and benefits of evolving a larger brain: Doubts over the evidence that large brains lead to better cognition. Anim. Behav. 4, e1-e3. doi: 10.1016/j.anbehav.2013.05.017

Heinze, S., Narendra, A., and Cheung, A. (2018). Principles of insect path integration. Curr. Biol. 28, R1043-R1058. doi: 10.1016/j.cub.2018.04.058

Herculano-Houzel, S., Collins, C. E., Wong, P., and Kaas, J. H. (2007). Cellular scaling rules for primate brains. Proc. Natl. Acad. Sci. U. S. A. 104, 3562-3567. doi: $10.1073 /$ pnas.0611396104

Herculano-Houzel, S., Mota, B., and Lent, R. (2006). Cellular scaling rules for rodent brains. Proc. Natl. Acad. Sci. U. S. A. 103, 12138-12143. doi: $10.1073 /$ pnas. 0604911103

Hibar, D. P., Stein, J. L., Renteria, M. E., Arias-Vasquez, A., Desrivières, S., Jahanshad, N., et al. (2015). Common genetic variants influence human subcortical brain structures. Nature 520, 224-229. doi: 10.1038/nature14101

Honkanen, A., Adden, A., da Silva Freitas, J., and Heinze, S. (2019). The insect central complex and the neural basis of navigational strategies. J. Exp. Biol. 222(Suppl. 1):jeb188854. doi: 10.1242/jeb.188854

Howard, J. J. (2001). Costs of trail construction and maintenance in the leaf-cutting ant Atta columbica. Behav. Ecol. Sociobiol. 49, 348-356. doi: $10.1007 / \mathrm{s} 002650000314$

Howard, J. J., Cazin, J., and Wiemer, D. F. (1988). Toxicity of terpenoid deterrents to the leafcutting ant Atta cephalotes and its mutualistic fungus. J. Chem. Ecol. 14, 59-69. doi: 10.1007/BF01022531

Hubbell, S. P., Howard, J. J., and Wiemer, D. F. (1984). Chemical leaf repellency to an attine ant: seasonal distribution among potential host plant species. Ecology 65, 1067-1076. doi: 10.2307/1938314

Kennedy, P., Baron, G., Qiu, B., Freitak, D., Helanterä, H., Hunt, E. R., et al. (2017). Deconstructing superorganisms and societies to address big questions in biology. Trends Ecol. Evol. 32, 861-872. doi: 10.1016/j.tree.2017.08.004

Kleineidam, C. J., Obermayer, M., Halbich, W., and Rössler, W. (2005). A macroglomerulus in the antennal lobe of leaf-cutting ant workers and its possible functional significance. Chem. Senses 30, 383-392. doi: 10.1093/chemse/bji033

Koch, S. I., Groh, K., Vogel, H., Hannson, B. S., Kleineidam, C. J., and GrosseWilde, E. (2013). Caste-specific expression patterns of immune response and chemosensory related genes in the leaf-cutting ant, Atta vollenweideri. PLoS ONE 8:e81518. doi: 10.1371/journal.pone.0081518

Kohno, H., and Kubo, T. (2019). Genetics in the honey bee: Achievements and prospects toward the functional analysis of molecular and neural mechanisms underlying social behaviors. Insects 10:348. doi: 10.3390/insects10100348

Li, Q., Wang, Z., Lian, J., Schiøtt, M., Jin, L., Zhang, P., et al. (2014). Caste-specific RNA editomes in the leaf-cutting ant Acromyrmex echinatior. Nat. Commun. 5:4943. doi: $10.1038 /$ ncomms5943

Lihoreau, M., Dubois, T., Gomez-Moracho, T., Kraus, S., Monchanin, C., and Pasquaretta, C. (2019). Putting the ecology back into insect cognition research. Adv. Insect Physiol. 57, 1-25. doi: 10.1016/bs.aiip.2019.08.002

Lihoreau, M., Latty, T., and Chittka, L. (2012). An exploration of the social brain hypothesis in insects. Front. Physiol. 3:442. doi: 10.3389/fphys.2012.00442 
Logan, C. J., Avin, S., Boogert, N., Buskell, A., Cross, A., Currie, A., et al. (2018). Beyond brain size: uncovering the neural correlates of behavioral and cognitive specialization. Comp. Cog. Behav. Rev. 13, 55-89. doi: 10.3819/CCBR.2018.130008

López-Riquelme, G. O., Malo, E. A., Cruz-López, L., and Fanjul-Moles, M. L. (2006). Antennal olfactory sensitivity in response to task-related odours of three castes of the ant Atta mexicana (hymenoptera: formicidae). Physiol. Entomol. 31, 353-360. doi: 10.1111/j.1365-3032.2006.00526.x

Mehdiabadi, N. J., and Schultz, T. R. (2010). Natural history and phylogeny of the fungus-farming ants (Hymenoptera: Formicidae: Myrmicinae: Attini). Myrmecol. News 13, 37-55.

Mikheyev, A. S., and Linksvayer, T. A. (2015). Genes associated with ant social behavior show distinct transcriptional and evolutionary patterns. Elife 4:e04775. doi: 10.7554/eLife.04775.016

Mizunami, M., Yamagata, N., and Nishino, H. (2010). Alarm pheromone processing in the ant brain: an evolutionary perspective. Front. Behav. Neurosci. 4:28. doi: $10.3389 /$ fnbeh. 2010.00028

Müller, M., and Wehner, R. (2010). Path integration provides a scaffold for landmark learning in desert ants. Curr. Biol. 20, 1368-1371. doi: 10.1016/j.cub.2010.06.035

Muscedere, M. L., and Traniello, J. F. A. (2012). Division of labor in the hyperdiverse ant genus Pheidole is associated with distinct subcaste-and age-related patterns of worker brain organization. PLOS ONE 7:e31618. doi: 10.1371/journal.pone.0031618

Paul, J., and Gronenberg, W. (1999). Optimizing force and velocity: mandible muscle fibre attachments in ants. J. Exp. Biol. 202, 797-808.

Paul, J., and Gronenberg, W. (2002). Motor control of the mandible closer muscle in ants. J. Insect Physiol. 48, 255-267. doi: 10.1016/S0022-1910(01)00171-8

Plath, J. A., and Barron, A. B. (2015). Current progress in understanding the functions of the insect central complex. Curr. Op. Insect Sci. 12, 11-18. doi: 10.1016/j.cois.2015.08.005

Powell, S., and Clark, E. (2004). Combat between large derived societies: a subterranean army ant established as a predator of mature leaf-cutting ant colonies. Insectes Soc. 51, 342-351. doi: 10.1007/s00040-004-0752-2

Provecho, Y., and Josens, R. (2009). Olfactory memory established during trophallaxis affects food search behaviour in ants. J. Exp. Biol. 212, 3221-3227. doi: 10.1242/jeb.033506

Qiu, B., Larsen, R. S., Chang, N. C., Wang, J., Boomsma, J. J., and Zhang, G. (2018). Towards reconstructing the ancestral brain gene-network regulating caste differentiation in ants. Nat. Ecol. Evol. 2:1782. doi: 10.1038/s41559-018-0689-x

Quiroga, R. Q., Reddy, L., Kreiman, G., Koch, C., and Fried, I. (2005). Invariant visual representation by single neurons in the human brain. Nature 435, 1102-1107. doi: 10.1038/nature03687

Rajakumar, R., Koch, S., Couture, M., Favé, M.J., Lillico-Ouachour, A., Chen, T., et al. (2018). Social regulation of a rudimentary organ generates complex worker-caste systems in ants. Nature 562, 574-577. doi: 10.1038/s41586-018-0613-1

Rajakumar, R., San Mauro, D., Dijkstra, M. B., Huang, M. H., Wheeler, D. E., Hiou-Tim, F., et al. (2012). Ancestral developmental potential facilitates parallel evolution in ants. Science 335, 79-82. doi: 10.1126/science.1211451

Real, L. A. (1993). Toward a cognitive ecology. Trends Ecol. Evol. 8, 413-417. doi: 10.1016/0169-5347(93)90044-P

Riveros, A. J., Seid, M. A., and Wcislo, W. T. (2012). Evolution of brain size in classbased societies of fungus-growing ants (Attini). Anim. Behav. 83, 1043-1049. doi: 10.1016/j.anbehav.2012.01.032

Ronacher, B., and Wehner, R. (1995). Desert ants Cataglyphis fortis use self-induced optic flow to measure distances travelled. J. Comp. Physiol. A 177, 21-27. doi: 10.1007/BF00243395

Rowe, C., and Healy, S. D. (2014). Measuring variation in cognition. Behav. Ecol. 25, 1287-1292. doi: 10.1093/beheco/aru090

Saverschek, N., Herz, H., Wagner, M., and Roces, F. (2010). Avoiding plants unsuitable for the symbiotic fungus: learning and long-term memory in leaf-cutting ants. Anim. Behav. 79, 689-698. doi: 10.1016/j.anbehav.2009. 12.021

Scholes, D. R., Suarez, A. V., and Paige, K. N. (2013). Can endopolyploidy explain body size variation within and between castes in ants? Ecol. Evol. 3, 2128-2137. doi: $10.1002 /$ ece 3.623
Schrader, L., Helanter,ä, H., and Oettler, J. (2017). Accelerated evolution of developmentally biased genes in the tetraphenic ant Cardiocondyla obscurior. Mol. Biol. Evol. 34, 535-544. doi: 10.1093/molbev/msw240

Schultner, E., and Pulliainen, U. (2020). Brood recognition and discrimination in ants. Insect. Soc. 1-24. doi: 10.1007/s00040-019-00747-3

Schultz, T. R., and Brady, S. G. (2008). Major evolutionary transitions in ant agriculture. Proc. Natl. Acad. Sci. U.S.A. 105, 5435-5440. doi: 10.1073/pnas.0711024105

Seid, M. A., Castillo, A., and Wcislo, W. T. (2011). The allometry of brain miniaturization in ants. Brain Behav. Evolut. 77, 5-13. doi: 10.1159/000322530

Shettleworth, S. (2010). Cognition, Evolution, and Behavior. New York, NY: Oxford University Press.

Shettleworth, S. J. (2000). "Modularity and the evolution of cognition," in The Evolution of Cognition, eds C. M. Heyes and L. Huber (Cambridge, MA: MIT Press), 43-60.

Shpigler, H. Y., Saul, M. C., Corona, F., Block, L., Ahmed, A. C., Zhao, S. D., et al. (2017). Deep evolutionary conservation of autism-related genes. Proc. Natl. Acad. Sci. U. S. A. 114, 9653-9658. doi: 10.1073/pnas.1708127114

Simons, M., and Tibbetts, E. (2019). Insects as models for studying the evolution of animal cognition. Curr. Opin. Insect Sci. 34, 117-122. doi: 10.1016/j.cois.2019.05.009

Smith, A. R., Kapheim, K. M., Pérez-Ortega, B., Brent, C. S., and Wcislo, W. T. (2013). Juvenile hormone levels reflect social opportunities in the facultatively eusocial sweat bee Megalopta genalis (Hymenoptera: Halictidae). Horm. Behav. 63, 1-4. doi: 10.1016/j.yhbeh.2012.08.012

Solomon, S. E., Rabeling, C., Sosa-Calvo, J., Lopes, C. T., Rodrigues, A., Vasconcelos, H. L., et al. (2019). The molecular phylogenetics of Trachymyrmex Forel ants and their fungal cultivars provide insights into the origin and coevolutionary history of 'higher-attine'ant agriculture. Syst. Entomol. 44, 939-956. doi: 10.1111/syen.12370

Sosa-Calvo, J., Schultz, T. R., JeŠovnik, A., Dahan, R. A., and Rabeling, C. (2018). Evolution, systematics, and natural history of a new genus of cryptobiotic fungus-growing ants. Syst. Entomol. 43, 549-567. doi: 10.1111/syen.12289

Steck, K. (2012). Just follow your nose: homing by olfactory cues in ants. Curr. Opin. Neurobiol. 22, 231-235. doi: 10.1016/j.conb.2011.10.011

Tomer, R., Denes, A. S., Tessmar-Raible, K., and Arendt, D. (2010). Profiling by image registration reveals common origin of annelid mushroom bodies and vertebrate pallium. Cell 142, 800-809. doi: 10.1016/j.cell.2010.07.043

Trible, W., Olivos-Cisneros, L., McKenzie, S. K., Saragosti, J., Chang, N. C., Matthews, B. J., et al. (2017). orco mutagenesis causes loss of antennal lobe glomeruli and impaired social behavior in ants. Cell 170, 727-735. doi: 10.1016/j.cell.2017.07.001

Via, S. E. (1977). Visually mediated snapping in the bulldog ant: a perceptual ambiguity between size and distance. J. Comp. Physiol. 121, 33-51. doi: 10.1007/BF00614179

Wartel, A., Lindenfors, P., and Lind, J. (2019). Whatever you want: Inconsistent results are the rule, not the exception, in the study of primate brain evolution. PLoS ONE 14:e0218655. doi: 10.1371/journal.pone.0218655

Wilson, E. O. (1980a). Caste and division of labor in leaf-cutter ants (Hymenoptera, Formicidae, Atta). 1. The overall pattern in Atta-sexdens. Behav. Ecol. Sociobiol. 7, 143-156. doi: 10.1007/BF00299520

Wilson, E. O. (1980b). Caste and division of labor in leaf-cutter ants (Hymenoptera: Formicidae: Atta). II: the ergonomic optimization of leaf cutting. Behav. Ecol. Sociobiol. 7, 157-165 doi: 10.1007/BF00299521

Wittlinger, M., Wehner, R., and Wolf, H. (2006). The ant odometer: stepping on stilts and stumps. Science 312, 1965-1967. doi: 10.1126/science.1126912

Conflict of Interest: The authors declare that the research was conducted in the absence of any commercial or financial relationships that could be construed as a potential conflict of interest.

Copyright (c) 2020 Muratore and Traniello. This is an open-access article distributed under the terms of the Creative Commons Attribution License (CC BY). The use, distribution or reproduction in other forums is permitted, provided the original author(s) and the copyright owner(s) are credited and that the original publication in this journal is cited, in accordance with accepted academic practice. No use, distribution or reproduction is permitted which does not comply with these terms. 